\title{
Strategies to reduce informal payments in health systems: a systematic review
}

\author{
Hamed Zandian, ${ }^{1}$ Atefeh Esfandiari, ${ }^{2}$ Minoo Alipouri Sakha ${ }^{3}$ and Amirhossein Takian $4,5,6$
}

${ }^{1}$ Social Determinants of Health Research Center, Ardabil University of Medical Sciences, Ardabil, Islamic Republic of Iran. ${ }^{2}$ Department of Health Policy \& Management, School of Medicine, Bushehr University of Medical Sciences, Bushehr, Islamic Republic of Iran. ${ }^{3}$ Department of Health Education \& Promotion, Deputy of Health, Iran University of Medical Sciences, Tehran, Islamic Republic of Iran. ${ }^{4}$ Department of Healthcare Management \& Economics; ${ }^{5}$ Department of Global Health and Public Policy, School of Public Health; ${ }^{6}$ Health Equity Research Center, Tehran University of Medical Sciences, Tehran, Islamic Republic of Iran (Correspondence to: Amirhossein Takian: takian@tums.ac.ir).

\begin{abstract}
Background: Informal payment is a major barrier to universal health coverage, particularly in low and middle-income countries.

Aims: The aim of this study was to determine appropriate methods to reduce informal payments in health care via a systematic review.

Methods: For this systematic review, we searched the Cochrane Library, PubMed and SCOPUS covering the period 2000-2014: 10 papers which considered reduction strategies for IP were finally included in the review. Three of the authors independently extracted data and assessed the papers against inclusion and exclusion criteria.

Results: Improving public awareness and measures towards changing the culture were the main policies to combat informal payment. In addition, providing additional financial support to motivate physicians and other health service providers, appropriate monitoring of legislation, and converting informal to formal payment through tailored new policies were other solutions mentioned towards reducing or removing informal payments.

Conclusions: No unique strategy exists for reducing informal payments in any health system. Choosing an appropriate strategy depends on the context and financing structure of the health system in any particular setting.

Keywords: informal payments, health care services, systematic review

Citation: Zandian H; Esfandiari A; Sakha M; Takian A. Strategies to reduce informal payments in health systems: a systematic review. East Mediterr Health J. 2019;25(12):914-922. https://doi.org/10.26719/emhj.19.057

Received: 01/05/17; accepted: 20/11/17

Copyright ( C) World Health Organization (WHO) 2019. Some rights reserved. This work is available under the CC BY-NC-SA 3.0 IGO license (https:// creativecommons.org/licenses/by-nc-sa/3.0/igo).
\end{abstract}

\section{Introduction}

Informal paymentis defined as the cost of health care services paid by the patients to services providers which is outside the scope of official tariffs (1). Some studies define informal payments as a tip for health staff, a bribe for access to better quality health care services, or payment demanded from health staff or establishments (2). Emerging evidence suggests that informal payments are an important feature of many health care systems around the world (3).

These payments are a threat to public health since they are highly regressive compared to formal fees (4) and those who cannot afford to pay informally might forgo or delay seeking treatment $(4,5)$; as a consequence efficiency, equity and quality of health care provision might be jeopardized. The custom of informal payments is inevitably linked with corruption (6) which may not only damage the relationship between doctor and patient seriously, but can lead to mistrust between the community and the health care team eventually (7).

Informal payment is one of the main barriers to achieving universal health coverage, particularly in the context of low middle-income countries. Available statistics from low-income countries indicate that 10$40 \%$ of out-of-pocket payment for health care services come from informal payments (1). This indicates the considerable amount of financial resources that are wasted instead of being used for health promotion purposes (6). For example, IPs are estimated to be equal to twice the salaries of doctors in Poland (8), while the revenues obtained from IP are 10 times greater than the official income of health care providers in Bangladesh (9) and 5 times that of those in Cambodia (10).

Overall, 3 major possible solution areas are suggested: cultural perceptions, insufficient funding of the health care sector and lack of control and accountability in the health care system (5).

Setting up a national health insurance supervisory authority to oversee the efficient management of the health care system, increased transparency and accountability $(11,12)$, punitive measures, higher salaries for health care workers and changes in attitudes of health care providers, consumers, and policy-makers via information campaigns $(5,13)$ are some of the strategies and policy initiatives that different countries have taken to address the problem.

This study reports the findings of a systematic review to identify the main strategies to reducing informal payments in health care systems. 


\section{Methods}

\section{Types of studies and data sources}

All published studies of any type of design (cross-sectional, cohort, qualitative, etc.) which reported data and suggested reduction strategies for informal payments in health systems were considered.

We performed a systematic literature search of 3 major databases during October 2015: PubMed, Cochrane Library, and Scopus, covering the period 2000-2014. We aimed to identify papers relevant to "reduction of informal payments". To increase the comprehensiveness of our search, we also checked the reference lists of all selected papers. Google Scholar was also used to find relevant technical documents and reports due to the lack of appropriate subheadings in Mesh. We did a preliminary search to identify common keywords that were used in the articles. In total, we identified 468 records, of which 10 fulfilled the eligibility criteria and were therefore included and assessed in our review (Figure 1).

\section{Inclusion and exclusion criteria}

We included reviews and original articles that were written in English, used any keywords mentioned in Box 1, and provided evidence for the reduction of informal payments in health system. Papers which were published

Figure 1 Summary of the data extraction process (PICO tool focuses on population, intervention, comparison and outcomes)
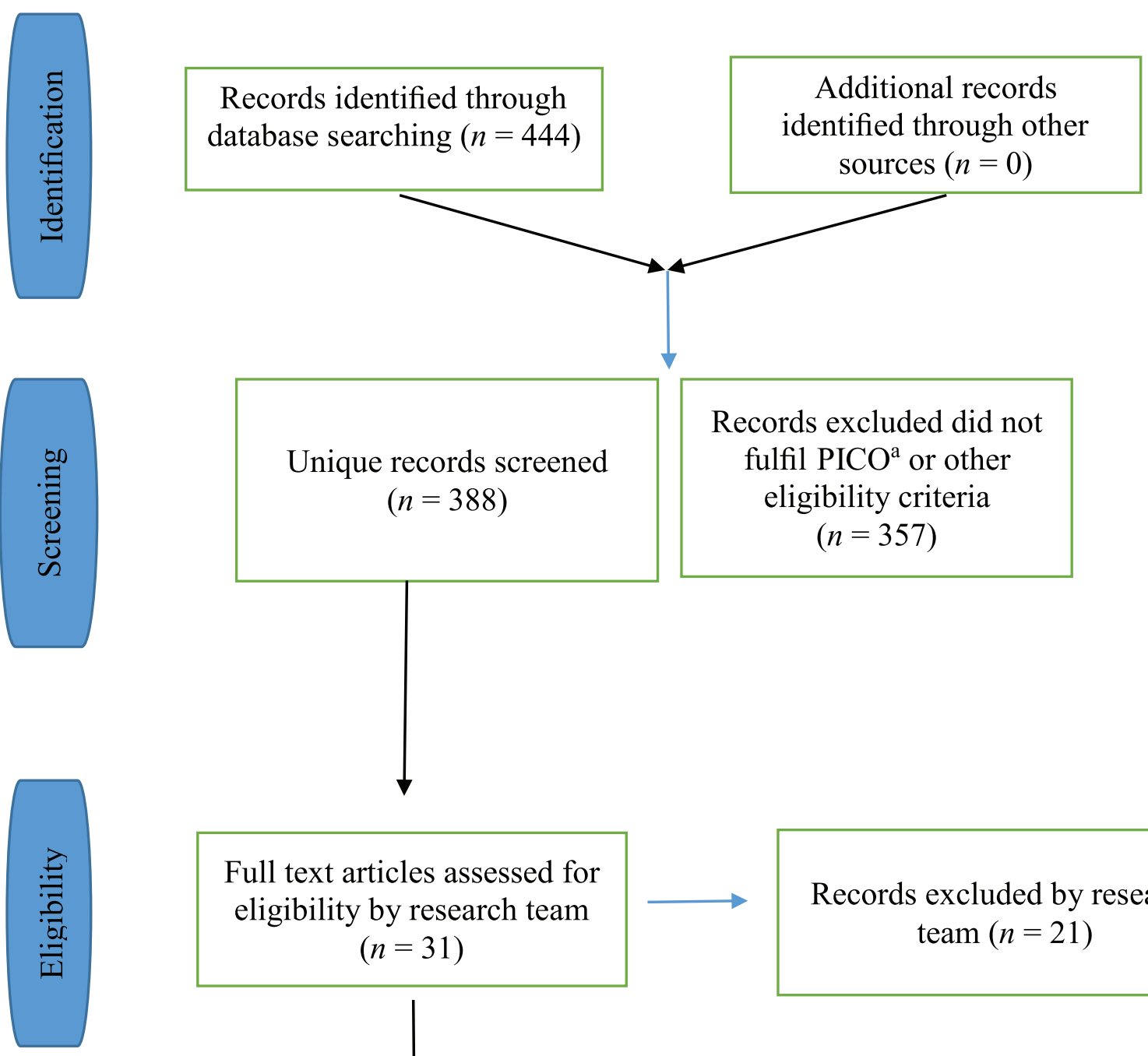

Full text articles assessed for eligibility by research team $(n=31)$

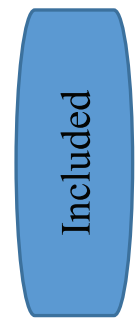

Articles included in qualitative synthesis $(n=10)$
Records excluded by research team $(n=21)$ 
prior to the year 2000, were not in English or did not mention or discuss ways to reduce informal payments were excluded.

\section{Critical appraisal process}

Three authors (HZ, MAS and AE) each followed the defined search strategy separately. The studies included were evaluated based on the CASP Systematic Review Checklist $(14,15)$. The quality of articles was assessed using a checklist that has been used in previous studies (14). The checklist consists of several questions about the purpose of the study, method of sampling, data collection strategy, population study, variables included, study method, method used for data analysis, outcomes, etc. Based on these questions, the quality of the studies was defined and the studies with high quality were included.

\section{Data extraction}

As explained in Figure 1, after deleting duplicates, 468 English language studies remained. The 3 authors screened these studies by title and abstract and reached agreement about $90 \%$ of articles. The eligible studies were then extracted and 31 papers remained. Following inclusion criteria and quality appraisal, we excluded 21 articles, and the 10 remaining papers were included in the review.

For the next step, we began to extract data from these 10 papers, i.e. authors' names, title, year of the study, the country where the study was conducted, the structure of the country's health system, the definition of informal payment, and the strategies mentioned to reduce informal payments.

\section{Findings}

\section{Description of studies}

We identified 10 studies that mentioned policies and actions to reduce informal payments, and these were included in the final synthesis. Four studies were qualitative; 3 were quantitative and 3 used mixed methods. The characteristics of the studies are described in Table 1. While low-, lower middle-, upper middle- and high-income countries were present in the final list of studies, the strongest evidence came from 6 studies conducted in 4 countries (Moldova, Albania, Hungary and Tanzania). Two studies were conducted in several countries simultaneously. Most studies were conducted during 2004-2015 and in the context of countries of the former Soviet Union (3,16-19). Two studies described the public's beliefs and attitudes towards informal payments $(13,16)$. One study considered IP as a barrier to essential health system reform, particularly universal health coverage (20). Another study reported the effects of health system reform on out-of-pocket payments through reducing informal payments (18) (Table 2).

In all, we synthesized 5 strategies and policies to reduce informal payments: cultural factors, quality factors, structural factors, legal factors and motivational factors. These are explained below and outlined in Table 3 .

\section{Legal factors}

The studies proposed reforms in health insurance law, the payment system (with emphasis on pay for performance), cost sharing and regulation and control of standards as appropriate policies to reduce informal payments in health systems.

Vian et al. studied the extent of out-of-pocket payments and informal payments, analysed their trends over time, and identified driving factors for informal payments in Moldova. They documented the gradually decreasing rate of informal payment over time, yet informal payment was recorded for a variety of reasons, e.g. patients' willingness to do informal payment as a gift to service providers, or their perception that informal payment may result in better quality and quicker care. Occasionally, informal payment existed because of irrational prescriptions for medications or ordering diagnostic tests, compelling health systems to implement effective strategies to reduce medicine prices and promote their rational use, strengthen administrative controls, and increase incentives for quality health care provision. Low payments to service providers (e.g. salaries) were another reason for informal payment, as indicated by data on salaries, so improved contracting

\begin{tabular}{|c|c|}
\hline Item & Questions \\
\hline \multirow[t]{5}{*}{ Validity of the systematic review results } & 1. Is the systematic review focused on a clear question? \\
\hline & 2. Were the authors looking for suitable articles? \\
\hline & 3. Were important and relevant studies included in this study? \\
\hline & 4. Did the authors assess the quality of articles adequately? \\
\hline & 5. Are the results of the combined studies reasonable? \\
\hline \multirow[t]{2}{*}{ The results of the systematic review } & 6. What were the total results of the systematic review? \\
\hline & 7. How much the results of the systematic review were accurate? \\
\hline \multirow{3}{*}{$\begin{array}{l}\text { The applicability of the results for the local } \\
\text { community }\end{array}$} & 8. Whether the results of the included studies can be generalized to the study context? \\
\hline & 9. Were all important outcomes considered? \\
\hline & 10. Are the options due to the losses and costs worth enough? \\
\hline
\end{tabular}

CASP = Critical Appraisal Skills Programme. 


\begin{tabular}{|c|c|c|c|}
\hline Author (publication year) & Study design & Country & Title \\
\hline Vian T et al. (2015) & Qualitative & Moldova & $\begin{array}{l}\text { Barriers to universal health coverage in Republic of Moldova: a policy } \\
\text { analysis of formal and informal out-of-pocket payments }\end{array}$ \\
\hline Vian T, Burak LJ (2006) & Qualitative & Albania & Beliefs about informal payments in Albania \\
\hline Baji P et al. (2013) & Quantitative & Hungary & $\begin{array}{l}\text { Exploring consumers' attitudes towards informal patient payments } \\
\text { using the combined method of cluster and multinomial regression } \\
\text { analysis - the case of Hungary }\end{array}$ \\
\hline Baji P et al. (2012) & Quantitative & Hungary & $\begin{array}{l}\text { Changes in equity in out-of-pocket payments during the period of } \\
\text { health care reforms: evidence from Hungary }\end{array}$ \\
\hline Balabanova D, McKee M (2002) & Mixed methods & Bulgaria & $\begin{array}{l}\text { Understanding informal payments for health care: the example of } \\
\text { Bulgaria }\end{array}$ \\
\hline Chereches R et al. (2011) & Mixed methods & Romania & $\begin{array}{l}\text { Informal Payments in the Health Care System - Research, Media and } \\
\text { Policy }\end{array}$ \\
\hline Gaal P, McKee M (2004) & Mixed methods & Hungary & $\begin{array}{l}\text { Informal payment for health care } \\
\text { and the theory of 'INXIT' }\end{array}$ \\
\hline Hotchkiss DR et al. (2005) & Quantitative & Albania & $\begin{array}{l}\text { Out-of-pocket payments and utilization of health care services in } \\
\text { Albania: evidence from } 3 \text { districts }\end{array}$ \\
\hline Ensor T (2004) & Qualitative & & Informal payments for health care in transition economies \\
\hline Kruk ME et al. (2008) & Qualitative & Tanzania & $\begin{array}{l}\text { User fee exemptions are not enough: out-of-pocket payments for } \\
\text { 'free' delivery services in rural Tanzania }\end{array}$ \\
\hline
\end{tabular}

mechanisms in national health insurance organizations for penalizing contractors or reducing the fees payable to health care providers who receive IPs might be used to tackle the problem.
Enhancing public awareness about their rights and the benefit package to which they are entitled (through promoting means of communication for the exchange of information to the insured) are very important,

\begin{tabular}{|c|c|}
\hline Theme & Subthemes \\
\hline \multirow[t]{5}{*}{ Structural factors } & Providing public resources for the health sector \\
\hline & Establishing social insurance system reforms in the health system \\
\hline & $\begin{array}{l}\text { Establishment of formal but flexible channels for voluntary participation of patients, including } \\
\text { sponsorship,advertising andsubscription contracts }\end{array}$ \\
\hline & Promoting means of communication for the exchange of information to insured \\
\hline & Making reform in patient-physician relationship \\
\hline \multirow[t]{4}{*}{ Legal factors } & Making reform in health insurance law \\
\hline & Making reform in payment system (emphasis on pay for performance) \\
\hline & Making reform in cost sharing \\
\hline & Making regulation and control standards \\
\hline \multirow[t]{2}{*}{ Quality factors } & Improving the quality of health care and access to public services \\
\hline & $\begin{array}{l}\text { receiving better and earlier treatment } \\
\text { Introduction of encouraging system for providers, i.e. quality assurance and performance evaluation }\end{array}$ \\
\hline \multirow[t]{4}{*}{ Cultural factors } & Informing the insured about the services and medicines covered by insurance and cost-sharing limit \\
\hline & $\begin{array}{l}\text { Altering the public attitudes by informing people about the percentage of medicine costs that are covered by } \\
\text { insurance and the equivalent generic medicines }\end{array}$ \\
\hline & $\begin{array}{l}\text { Altering the public attitudes by informing the insured about the way of access to complaints and compensation } \\
\text { mechanisms }\end{array}$ \\
\hline & $\begin{array}{l}\text { Altering the beliefs of insured that informal payments are not necessary to receive quality services, convincing } \\
\text { the public that governments employees' salary are enough to do so }\end{array}$ \\
\hline \multirow[t]{2}{*}{ Motivational factors } & Establishing rewards and punishment system \\
\hline & $\begin{array}{l}\text { Collecting informal payments at the team level and then distributing it among medical personnel to remove } \\
\text { disparities in receiving informal payments among experts }\end{array}$ \\
\hline
\end{tabular}


especially within vulnerable groups. Revision of payment systems for increasing providers' motivation, with an emphasis on pay for performance, is a good strategy to eliminate informal payment. In Mongolia and Vietnam, organizations were encouraged to provide grants for increasing transparency (20). In fact, strengthening governance and reducing expectations for informal payment in all sectors through government policies, i.e. enhanced transparency and accountability, with a particular focus on the supply side, including health care providers, are fundamental important policies in this area (20).

Reasonable copayments by people when receiving health care services, promoting the knowledge of the insured and informing them about complaint procedures are also crucial. Baji et al. studied prepayment household spending on health during the reform period, particularly the cost of medicines and medical equipment and official and unofficial payments. They concluded that implementing copayment in the Eastern European and Central European countries was an important strategy towards eradicating informal payment (13).

\section{Cultural factors}

Improving public education to enhance their knowledge about insurance coverage, services, medicines and the extent of cost sharing, as well as their access to complaints and compensation mechanisms, may help users change their attitude and avoid informal payments, while still expecting to receive better quality services.

Through the lens of the theory of planned behaviour, Vain et al. studied people's attitudes and beliefs to predict their intention to give informal payment. They compared people who intended to make informal payments with people who did not intend to do so in Albania. They found that most participants knew that informal payment was illegal. Hence, they found little effect on reducing informal payment through only saying to people that informal payment is wrong and a sign of corruption. The authors suggested behavioural change strategies as an alternative choice to modify the public's beliefs about the need for informal payment to ensure quality services. This strategy attempts to convince people that government employees' salaries are enough to ensure quality of services. They also suggest penalizing the recipients of informal payments, so asking for such payments may become a shameful act (16).

Baji et al. studied consumers' opinion about informal payment in Hungary (13). Their findings identified some necessary steps to deal with informal payment, i.e. changing attitudes towards this phenomenon from positive to negative, improving quality of health care and enhancing access to public services through the provision of public resources to enjoy such services.

\section{Quality factors}

Vian et al. advocated quality improvement programmes, e.g. having a clear reporting system in place as a useful policy to reduce informal payment. They concluded that patients are willing to pay informal payment in expectation of receiving better and timelier treatment (16). Improving the quality of health care and access to public services (13), and the introduction of a system of encouragements for providers such as quality assurance and performance evaluation (17) were among the strategies that were proposed to reduce informal payment.

\section{Structural factors}

Balabanova et al. estimated the scale and determinants of informal payment in the health sector of Bulgaria (21). They identified the beneficiaries, characteristics and timing of payments as the main reasons for informal payment. They suggested wide reforms in the health system, i.e. a functioning social insurance system, official methods of payment by consumers, providing public resources for the health sector, establishment of formal but flexible channels for patients' voluntary participation, e.g. sponsorship, advertisement, subscription contracts, promoting means of communication for the exchange of information to the insured and making reforms in patient-physician relationships (focus on removing the financial relationship) as effective policies to reduce informal payment.

Gaal et al. conducted a theoretical study of informal payment in the Hungarian health system and suggested some strategies on the basis of INXIT theory, which considers informal payment as an exit strategy within the organization (19). They include: voluntary declaration by physicians, prohibition and regulatory pressures imposed by the authorities, increased payments to physicians for appropriate financing, patients' free choice for service provider, using various forms of partnership, employing output-based payments to providers, substantial restrictions on social security and providing pre-funded services.

Hotchkiss et al. indicated doctors' monopoly as a main contributor to informal payment and found no difference between rich and poor nor between urban and rural people with regard to out-of-pocket payments in Albania, where informal payment comprised 24.7\% of total health expenditure (17). Among those who made informal payments, $95 \%$ stated that they did so voluntarily and this involved up to $0.6 \%$ of the monthly household income. The study revealed significant differences between inpatient and outpatient services and identified some reasons for reducing informal payment, i.e. the effectiveness of Albania's health insurance programme to increase access to primary health care services through salaries for doctors and family physicians along with providing subsidies for primary health care services, visits and medicines. The increased insurance coverage during recent years has led to reducing informal payment for services and medicines. However, the insurance coverage has not affected the number of visits to use basic health services. The study identified lack of awareness in insured people about their rights as an encouraging factor for informal payment and suggested some solutions for its reduction, including initiating informal 
payment reduction from hospitals and inpatients services, strengthening primary health care service and interrupting the financial relationship between doctors and patients. The relationship between socioeconomic status and the amount of informal payment indicates that the system should pay considerable attention to vulnerable people.

Kruk proposed payment for services provided to women, i.e. offering coupons (voucher) during a special programme and contracting with private providers to enhance care coverage and equity as effective solutions to reduce informal payment (22). In addition, subsidizing private facilities and services may enable them to reduce their fees, hence increasing the target population's access to needed services.

\section{Motivational factors}

Establishing a system of incentives and disincentives as well as collecting informal payment at the team level and then distributing it among involved personnel is a motivational initiative to remove disparities in IPs received by various health professionals. Hotchkiss et al. suggested a number of strategies for reducing informal payment: institutionalizing the capacity of identifying and punishing physicians who are accused of receiving informal payment, formulating appropriate strategies for households payments, introducing a motivational system for providers such as quality assurance and performance evaluation, promoting knowledge and awareness about the rights of patients and accountability, particularly on health insurance benefits (17).

Ensor proposed punishing doctors who are accused of receiving informal payment (23). This strategy needs serious attention as it may lead to a reluctance to work in the public sector among physicians and encourage a greater willingness to join the private sector. Official recording of all payments made in the health system can help reduce informal payment. This strategy has a risk of increasing the cost of the formal sector. However, competition may be increased through effective legislation pathways. Developing a transparent system about patients' rights, a simple complaints process, transparent contracts for physicians and targeting facilities are other useful strategies.

Governments should pay greater attention to the local characteristics of the health system to avoid implementing ineffective strategies. Ensor extracted 5 ways to reduce informal payment from various studies, and explained the advantages, disadvantages and different effects of each choice, as listed below (23):

- regulation and control standards to punish offenders;

- adjusting and legislation by specialized entities;

- encouraging increasing the share of market-based control to create positive incentives for good behaviour;

- disclosing the names of violators;

- the rights and obligations of physician in patient rights laws.

\section{Discussion}

Our study sought to analyse key policies and strategies to reduce informal payment in health systems. Various studies show that demand-side informal payments have

\footnotetext{
Box 1 Electronic search strategy

PubMed, October 2015

Results: 145 hits: (((““informal payments" OR "under-the-counter payments” OR "out-of-pocket payments”, OR "under-the-table payments” OR "envelope payments" OR gifts OR "illicit payments" OR “solicited payments" OR "gratuities" OR "illegal payments" OR "unofficial payments" OR " Unofficial fees" OR bribes OR donations OR " in cash" OR "in kind" OR " gratitude money" OR " Unofficial healthcare fees" OR " unauthorized fee payments" OR " quasi-official payments" OR " grey payments" OR " gift-in-kind" OR "informal patient payments" OR "corruption in health care" OR "gratuity for doctors")))) AND ((“"health care" OR" Healthcare services receivers "OR "healthcare services providers" OR " health system")))) AND ((((reduction OR elimination OR decrease OR reduce OR decline OR rebate OR scale down OR diminution OR eradication OR policy strategies))))

Scopus, October 2015

Results: 193 hits (TITLE-ABS-KEY ("informal payments" OR "under-the-counter payments" OR "out-of-pocket payments", or "under-the-table payments" OR "envelope payments" OR gifts OR "illicit payments" OR "solicited payments") OR TITLE-ABS-KEY ("gratuities" OR "illegal payments" OR "unofficial payments" OR " Unofficial fees" OR bribes OR donations OR " in cash" OR " in kind" OR " gratitude money" OR " Unofficial healthcare fees" OR " unauthorized fee payments" OR " quasi-official payments") OR TITLE-ABS-KEY (" grey payments" OR " gift-in-kind" OR "informal patient payments" OR "corruption in health care" OR "gratuity for doctors") AND TITLE-ABS-KEY ("health care" OR " Healthcare services receivers" OR "healthcare services providers" OR " health system") AND TITLE-ABS-KEY (reduction OR elimination OR decrease OR reduce OR decline OR rebate OR scale down OR diminution OR eradication OR policy)) AND SUBJAREA (mult OR medi OR nurs OR vete OR dent OR heal OR mult OR arts OR busi OR deci OR econ OR psyc OR soci) AND PUBYEAR > 1999

Cochrane Library,

Results: 106 hits: \#1 "informal payments", \#2"under-the-counter payments", \#3"out-of-pocket payments", \#4"under-the-table payments", \#5"envelope payments",\#6" gifts", \#7"illicit payments", \#8"solicited payments", \#9"gratuities", \#10"illegal payments", \#11"unofficial payments", \#12"Unofficial fees", \#13"bribes", \#14"donations", \#15"in cash", \#16,"in kind", \#17 "gratitude money", \#18 "Unofficial healthcare fees", \#19 "unauthorized fee payments", \#20 "quasi-official payments", \#21" grey payments", \#22"gift-in-kind", \#23"informal patient payments", \#24"corruption in health care", \#25"gratitude for doctors",\#26: \#1 OR \#2 OR \#3 OR \#4 OR \#5 OR \#6 OR \#7 OR \#8 OR \#9 OR \#10 OR \#11 OR \#12 OR \#13 OR \#14 OR \#15 OR \#16 OR \#17 OR \#18 OR \#19 OR \#20 OR \#21 OR \#22 OR \#23 OR \#24 OR \#25, \#27 "health care", \#28 "health care services receivers", \#29 "health care services providers", \#30 "health system", \#31: \#27 OR \#28 OR \#29 OR \#30, \#32 reduction ,\#33 elimination, \#34 decrease, \#35 decline, \#36 rebate, \#37 scale down, \#38 diminution, \#39 eradication, \#40 policy strategies, \#41 reduce, \#42:\#32 OR \#33 OR \#34 OR \#35 OR \#36 OR \#37 OR \#38 OR \#39 OR \#40 OR \#41

\#43 \#26 AND \#31 AND \#42
} 
different reasons such as: fear of poor quality, desire for faster care, patients' wish to appreciate providers, health care providers' low payment, lack of awareness of the insured with respect to their rights and positive attitude to this phenomenon. In a study by Amiresmaili et al., some reasons are found for demand-side informal payments such as cultural, quality-related and legal factors, and some reasons were identified for supply-side payments such as tariffs, structural and moral reasons, and to demonstrate competence (24). One of the main drivers of informal payment on the service provider's side is monopoly position of physicians. A study conducted in Albania suggests strategies such as strengthening primary health care and banning financial interactions between physicians and patients (19).

The main strategies mentioned in the studies were providing the insured with information on covered services and medicines, permitted copayments, percentage of the cost of services through the improvement of methods and instruments for communication of information, increasing knowledge of insured patients on how to access grievance redress mechanisms, enhance awareness of their rights and break the chains of their beliefs about the need to make unofficial payments to get quality care (20), and simplifying the process for complaints (17).

Most studies pointed out regulatory reforms and strengthening monitoring mechanisms as important strategies to reduce informal payment. Amending health insurance law to pose penalties on the demand for informal payment as an attempt on abusing the rights of the insured, and reassuring people of punishments for physicians who receive informal payment (20), regulatory pressures imposed by the authorities, prefunded services (25), and increasing the ability of stewardship to identify and punish physicians who are accused of receiving informal payment (19), were other solutions that were mentioned to tackle the problem.

Our findings showed that without adopting other required strategies, some solutions might result in inappropriate outcomes. For example, demand-side strategies such as simplifying the complaint process, to deal with physicians misusing of their monopoly position and banning their financial relationship with patients, require strengthening regulatory supervision. A study in Albania suggests that cutting the financial relationship between physicians and patients, along with with increasing the capacity of stewardship of the health system can identify and warn the physicians who are accused of receiving informal payment (20). The poor payment system and lack of contracting with doctors and other service providers are other causes of informal payment. In this regard, 6 studies pointed to payment systems reform for providers and strengthening contractual provisions as strategies to consider.

Making transparent contracts with physicians (17) and private health care providers (23), increasing incentives for service providers through the revision of payment structure with an emphasis on performance-based payment $(20,25)$, retaining informal payment at the team level and sharing it with other health care providers to remove disparities among experts (18), and implementing appropriate revisions in payment systems, e.g. increasing salaries (25), were other strategies that were proposed to reduce informal payment.

Some studies highlighted provision of services to reduce informal payment, i.e. improving quality of health care and access to public services (16), introducing a mechanism for promoting quality assurance and performance evaluation (19). Other studies emphasized financing and cost sharing areas to remove informal payment. For instance, formulating payments through appropriate and effective copayment household strategies $(19,25)$; development of formal and flexible channels for voluntary participation to develop copayments (13,21); subsidizing primary health care (19) as well as private facilities and services to increase the target population's access to services, hence eventually reducing informal payment (23).

Our review revealed the use of mixed solutions according to the contextual characteristics of various countries. A considerable portion of the research on informal payment comes from transitional economies in Eastern Europe,e.g. Albania, Hungary and Bulgaria, or low-income countries, e.g. Moldova and Tanzania. We found no evidence from high-income countries, or middle-income countries in parts of the world other than Eastern Europe, thus the implementation of these strategies in other contexts needs some caution.

The strengths of this systematic review include using a comprehensive search strategy and robust evaluation of extracted articles that accommodates a wide range of beliefs and attitudes about informal payment to investigate the means for its reduction. The major value of this study is in providing a summary of the most important strategies recommended or used to reduce informal payment. The study also sets out the appropriate options available to policy-makers to tackle informal payment and highlights that only one strategy may be ineffective, so a tailored mix of strategies is recommended. Country-specific features should be taken into account to in application of these strategies in different settings. The present review highlights that well-designed studies are required for the identification of main causes of informal payment and the impact of various factors such as context and social, cultural and health system structures. It is also necessary to study in the low-income countries in term of considering the main causes of informal payment in comparing with other middle- and high-income countries.

Our study has certain limitation. First, we collected only evidence that was published in English so we may have missed studies in other settings that were reported in other languages. Second, since informal payment is a sensitive issue, the amount of which is not usually reported in the health system, the extent of the research on policies and strategies to reduce IP might seem limited. 


\section{Conclusions}

We found no unique strategy among the research we reviewed for tackling IP; choosing an appropriate strategy depends on the context and financing structure of the health system in various settings. As a number of countries have begun to move towards universal health coverage as a part of their commitment to comply with the Sustainable Development Goals by 2030, each country has to implement strategies that accord with its contextual characteristics and roots to tackle IP as a main barrier to financial protection and universal health care.

Funding: This study was funded by National Institutes of Health Research, Tehran University of Medical Sciences, grant number 241/4/93201.

Competing interests: None declared.

\section{Stratégies visant à réduire les paiements informels dans les systèmes de santé : analyse systématique}

\section{Résumé}

Contexte : Les paiements informels représentent un obstacle majeur à la couverture sanitaire universelle, en particulier dans les pays à revenu faible et intermédiaire.

Objectif : L'objectif de la présente étude était de déterminer des méthodes appropriées pour réduire les paiements informels dans les soins de santé par le biais d'une analyse systématique.

Méthodes : Pour la présente analyse systématique, nous avons fait des recherches dans la Cochrane Library, PubMed et SCOPUS couvrant la période 2000-2014 : 10 articles de recherche qui envisageaient des stratégies de réduction des paiements informels ont finalement été inclus dans l'analyse. Trois des auteurs ont extrait les données et ont évalué ces articles de façon indépendante par rapport aux critères d'inclusion et d'exclusion.

Résultats : L'amélioration de la sensibilisation du public et les mesures visant à changer la culture ont été les principales politiques de lutte contre les paiements informels. En outre, la fourniture d'un soutien financier supplémentaire pour motiver les médecins et les autres prestataires de services de santé, un suivi approprié de la législation et la conversion des paiements informels en paiements formels par le biais de nouvelles politiques adaptées sont d'autres solutions mentionnées pour réduire ou supprimer ce type de paiements.

Conclusions : Il n'y a pas de stratégie unique pour réduire les paiements informels dans quelque système de santé que ce soit. Le choix d'une stratégie appropriée dépend du contexte et de la structure de financement du système de santé dans un contexte particulier.

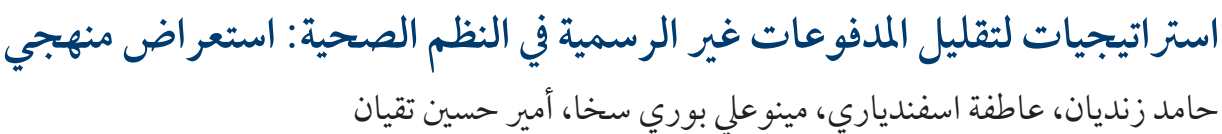

$$
\begin{aligned}
& \text { الخلفية: يُعدّ دفع مبالغ مالية بصفة غير رسمية عائقاً كبيراً أمام التغطية الصحية الشاملة، لا سيا في البلدان ذات الدخل المنخفض والمتوسط. } \\
& \text { الأهداف: هدفت هذه الدراسة إلى تحديد طرق مناسبة لتقليل المدفوعات غير الرسمية في نظام الرعاية الصحية من خلال استعراض منهجي. }
\end{aligned}
$$

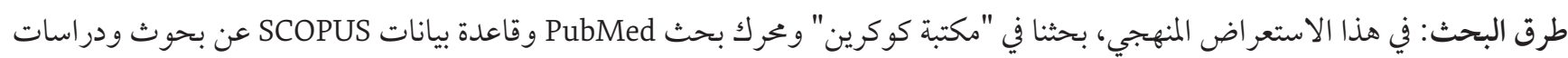

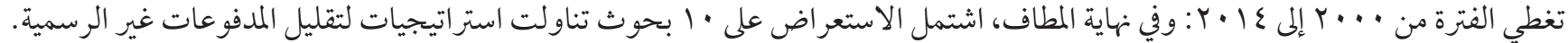

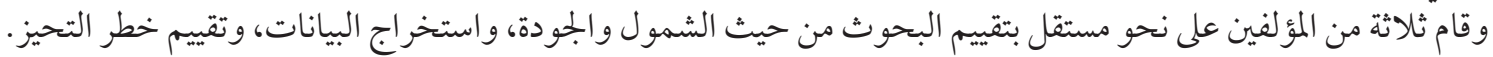

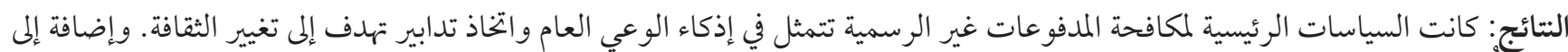

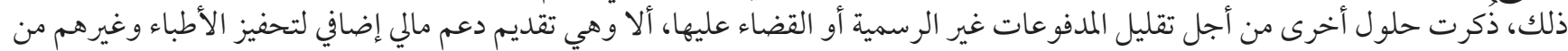

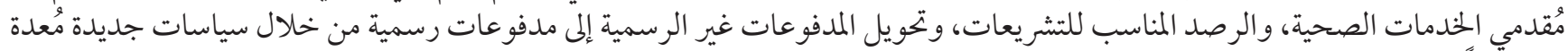
خصو صاً لذلك.

الاستنتاجات: لا توجد استراتيجية وحيدة لتقليل المدفوعات غير الرسمية في أي نظام صحي. بل يعتمد اختيار الاستراتيجية المناسبة على ظروف

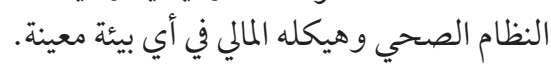




\section{References}

1. Onwujekwe O, Dike N, Uzochukwu B, Ezeoke O. Informal payments for healthcare: differences in expenditures from consumers and providers perspectives for treatment of malaria in Nigeria. Health Policy. 2010;96(1):72-9. doi: 10.1016/j. healthpol.2009.12.014

2. Stepurko T, Pavlova M, Gryga I, Groot W. Empirical studies on informal patient payments for health care services: a systematic and critical review of research methods and instruments. BMC Health Serv Res. 2010;10(1):273. doi:10.1186/1472 - 6963 - 10 273

3. Gaal P, Belli PC, McKee M, Szocska M. Informal payments for health care: definitions, distinctions, and dilemmas. J Health Polit, Policy Law. 2006;31(2):251-93. doi:10.1215/03616878-31-2-251

4. Szende A, Culyer AJ. The inequity of informal payments for health care: the case of Hungary. Health Policy. 2006;75(3):262-71. doi:10.1016/j.healthpol.2005.04.001

5. Pavlova M, Stepurko T, Gordeev VS, Tomini S, Gryga I, Groot W. Informal patient payments for health care services: policy challenges and strategies for solutions. Zdrowie Publiczne i Zarządzanie. 2010;8(1):5-11.

6. Liaropoulos L, Siskou O, Kaitelidou D, Theodorou M, Katostaras T. Informal payments in public hospitals in Greece. Health Policy. 2008;87(1):72-81. doi:10.1016/j.healthpol.2007.12.005

7. Bagheri A. Iranian medical ethics priorities: results of a national survey. Med Ethics and History Med. 2011;4(5):39-48 (http:// ijme.tums.ac.ir/article - 1 - 157 - en.html, accessed 21 April 2019).

8. Chawla M, Berman P, Windak A, Kulis M. Provision of ambulatory health services in Poland: a case study from Krakow. Soc Sci Med. 2004;58(2):227-35. PMID:14604609

9. Killingsworth JR, Hossain N, Hedrick - Wong Y, Thomas SD, Rahman A, et al. Unofficial fees in Bangladesh: price, equity and institutional issues. Health Policy Plan. 1999;14(2):152-63. PMID:10538718

10. Barber S, Bonnet F, Bekedam H. Formalizing under - the - table payments to control out - of - pocket hospital expenditures in Cambodia. Health Policy Plan. 2004;19(4):199-208. PMID:15208276

11. Baji P, Pavlova M, Gulácsi L, Groot W. User fees for public health care services in Hungary: expectations, experience, and acceptability from the perspectives of different stakeholders. Health Policy. 2011;102(2):255-62. doi:10.1016/j. healthpol.2011.03.001

12. Gaitonde R, Bjørndal A, Oxman AD, Okebukola PO, Ongolo-Zogo P. Interventions to reduce corruption in the health sector. Cochrane Database Syst Rev. 2010;11. doi:10.1002/14651858.CD008856.pub2

13. Baji P, Pavlova M, Gulacsi L, Groot W. Exploring consumers' attitudes towards informal patient payments using the combined method of cluster and multinomial regression analysis - - the case of Hungary. BMC Health Serv Res. 2013;13:62. doi:10.1186/1472-6963-13-62

14. Systematic Review Study Group. CASP critical appraisal skill programme. 2018 (https://casp - uk.net/casp - tools - checklists/, Accessed 29 May 2019).

15. Zeng X, Zhang Y, Kwong JS, Zhang C, Li S, Sun F, et al. The methodological quality assessment tools for preclinical and clinical studies, systematic review and meta - analysis, and clinical practice guideline: a systematic review. J Evid Based Med. 2015;8(1):2-10. doi:10.1111/jebm.12141

16. Vian T, Burak LJ. Beliefs about informal payments in Albania. Health Policy Plan. 2006;21(5):392-401. doi:10.1093/heapol/ czl022

17. Hotchkiss DR, Hutchinson PL, Malaj A, Berruti AA. Out - of - pocket payments and utilization of health care services in Albania: evidence from three districts. Health Policy. 2005;75(1):18-39. doi:10.1016/j.healthpol.2005.02.003

18. Baji P, Pavlova M, Gulacsi L, Groot W. Changes in equity in out - of - pocket payments during the period of health care reforms: evidence from Hungary. Int J Equity Health. 2012;11:36. doi:10.1186/1475 - 9276-11- 36

19. Gaal P, McKee M. Informal payment for health care and the theory of 'INXIT'. Int J Health Plan Manage. 2004;19(2):163-78. doi:10.1002/hpm.751

20. Vian T, Feeley FG, Domente S, Negruta A, Matei A, Habicht J. Barriers to universal health coverage in Republic of Moldova: a policy analysis of formal and informal out - of - pocket payments. BMC Health Serv Res. 2015;15:319. doi:10.1186/s12913 $015-0984-z$

21. Balabanova D, McKee M. Understanding informal payments for health care: the example of Bulgaria. Health Policy. 2002;62(3):243-73. PMID:12385850

22. Kruk ME, Mbaruku G, Rockers PC, Galea S. User fee exemptions are not enough: out - of - pocket payments for 'free' delivery services in rural Tanzania. Tropical Med Int Health. 2008;13(12):1442-51. doi:10.1111/j.1365 - 3156.2008.02173.x

23. Ensor T. Informal payments for health care in transition economies. Soc Sci Med. 2004;58(2):237-46. PMID:14604610

24. Amiresmaili M, Nekoeimoghadam M, Esfandiari A, Ramezani F, Salari H. Causes of informal payments in health sector: a qualitative study of viewpoints of physicians, policy makers and patients. Iranian J Med Ethics History Med. 2013;6(3):72-83.

25. Cherecheş R, Ungureanu M, Rus I, Baba C. Informal payments in the health care system - research, media and policy. Transylvanian Rev Administrative Sci. 2011;7(32):5-14 